\title{
Comparison and analysis of different conduction modes of three phase voltage source inverter
}

\author{
Purvi Chandrakar \\ Department of Energy and Environmental Engineering, University Teaching Department, Chhattisgarh \\ Swami Vivekanand Technical University, Bhilai, Chhattisgarh, 491107, India. \\ Email: pcpoorvichandrakar@gmail.com \\ Received July 1, 2019; received in Revised form July 15, 2019; Accepted July 23, 2019, Available online July 2019
}

\begin{abstract}
A Simulink model for voltage source inverter using switching function concept is studied with the help of MATLAB/SIMULINK in this paper. The switching function concept is a powerful tool in understanding and optimizing the performance of static power converters/inverters. A three phase output can be obtained from a configuration of six IGBT. Three types of control signals can be applied to the switched: 1800 conduction, 1200 conduction or 1500 conduction. The output voltages and current of a three phase voltage-source inverter is studied in this paper. The quality of output voltage can be improved by only changing the conduction mode which is very simple to implement. The switching operation of a three phase inverter is controlled so that output is achieved at every 600 angle in 1200, 1800, 1500 conduction mode. Harmonics are created in the output of these kind of inverter. These harmonics not only reduces the life period of appliances, but also causes excessive wear in the device or appliances used in the day to day life of human being. By analyzing the output harmonic spectra of output voltages and current (line to line current and line to line voltages), their total harmonic distortion (THD) is found and compared.
\end{abstract}

Keywords: Voltage source inverter, Conduction mode, Total harmonic distortion, Line voltage, FFT analysis

\section{Introduction}

In the field of Power-Electronics, inverter is the class of power conversion circuits. They have input of a dc current/voltage source and have symmetric ac voltage or current as their output. It can be said that it does reverse process of what ac to dc converter does. The input to the inverter can be a dc source derived from an ac source or direct dc source. For example, in utility supplies as the primary source of input power is an ac voltage supply. This is then changed to dc by an ac-dc rectifier. A filter capacitor may be also used for this case. This dc is then converted back to ac using a dc to ac converter also known as inverter. The magnitude and frequency of the final ac output may be different from the previous ac input of the utility. A current source inverter (CSI) is the inverter whose input is a source with constant current and variable voltage. Similarly a Voltage Source Inverter (VSI) is where the input voltage is maintained constant by using a constant voltage source. The Voltage Source Inverter circuit has direct control over output voltage whereas the current source inverter directly controls output current. Similarly, in a variable dc linked inverter the input voltage is controllable. Block diagram of VSI is shown in Figure 1.

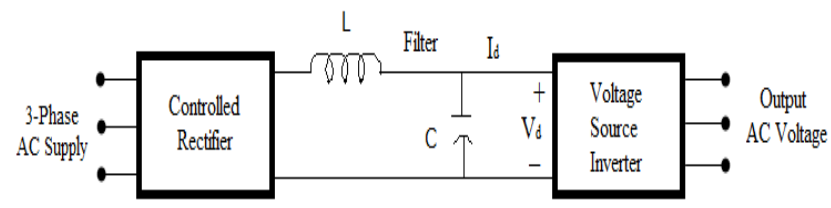

Figure 1 Block Diagram of Voltage Source Inverter (VSI) 
Semiconductor devices with hihg power rating are used in these converters as switching devices. When closed, these devices act as short circuit due to their characteristics [1]. An Ideal switch is the one which consumes very less power when switched from one state to another. Semiconductors are those materials whose conductivity will increase or decrease based on the energy falling on to its surface. As the temperature increases, more heat energy is absorbed by the semiconductor material and hence more current is conducted by the semiconductor. Also they do not conduct at absolute zero temperature. The more there is rise in temperature, more the current rise. Some example of these kind of switches are diode, silicon controlled rectifier (SCR), metal-oxidesemiconductor field-effect transistor (MOSFET), insulated-gate bipolar transistor (IGBT), bipolar junction transistor (BJT), TRIAC etc.

Classification of semiconductor devices [2]

- Based on controllability

1. Un-controlled

2. Semi controlled

3. Fully controlled

- Based on control modes

1. Current controlled (BJT, SCR)

2. Voltage controlled (IGBT, MOSFET)

- Based on current direction

1. Unidirectional (SCR, MOSFET, IGBT)

2. Bidirectional (TRIAC)

An Insulated Gate Bipolar Transistor (IGBT) is a power semiconductor device having three terminals. It is primarily used as an electronic switch. It was developed to have high efficiency and fast switching. It has many modern appliances in switching electric power. IGBT has the advantages of both MOSFETs and BJTs. An IGBT has low on state conduction losses and high input impedance. To turn on an IGBT we need to apply a positive gate voltage. This opens the channel for $\mathrm{n}$ carriers. Removing the gate voltage turns off the IGBT. It has lower conductive and switching losses because of the reasons stated above. So an IGBT is faster than a BJT. The switching frequency can be upto 20 $\mathrm{Khz}$ and the rating for single IGBT can be upto $1200 \mathrm{~V}, 400 \mathrm{~A}$. We have used IGBT for our simulation purpose.

\section{Three Phase VSI}

Many industries use three phase six-switch inverters. They are used in

- variable speed ac motor drives,

- induction heating,

- standby power supplies,

- uninterruptible power supplies

Different types of fault that commonly occur in these inverters have been investigated recently [3]. The most important of these is reducing harmonic distortion and the improvement of the output waveform. Therefore different types of inverters are presented having different structures, which can reduce harmonic and can lead to improve the output voltage too. The power circuit diagram for three phase bridge voltage source inverter is shown in Fig. 2

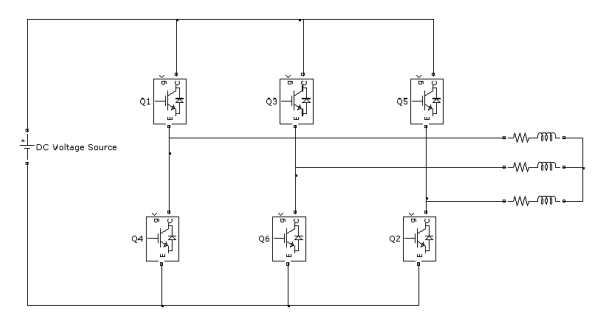

Figure 2 Three Phase Voltage Source Inverter

For high-power three phase systems, typical outputs are 
(1) $220 \mathrm{~V}$ to $380 \mathrm{~V}$ at $50 \mathrm{~Hz}$.

(2) $120 \mathrm{~V}$ to $208 \mathrm{~V}$ at $60 \mathrm{~Hz}$.

(3) $115 \mathrm{~V}$ to $200 \mathrm{~V}$ at $400 \mathrm{~Hz}$

This inverter improves the output voltage and current quality. But it has the disadvantage that using this conduction mode will increase both size and weight of inveter, which will inturn causes rise in price. Thus inverters with conductive angles $120^{\circ}, 180^{\circ}$ and $150^{\circ}$ are used for all 3 phase six- switch inverters.

\section{$2.11^{0}{ }^{\circ}$ Conduction Mode Three phase VSI}

It is a very common thyrister firing technique. In this technique the duration for which in one leg of inverter only one thyristor conducts for $180^{\circ}$. Hence at any time 3 thyristors remain $\mathrm{ON}$ [2]. Suppose in first leg of inverter, if $Q_{1}$ is turned on, phase "a" of load is connected to to positive terminal $(+\mathrm{V} / 2)$ of dc input voltage. Similarly if we turn on thyristor $\mathrm{Q}_{4}$ phase "a" will be connected to the negative terminal (-
$V / 2$ ) of the dc source. Phase "b" and "c" follows the similar sequence. There will be 6 operating pattern within the 2-cycle. There will be $60^{\circ}$ interval for each pattern. The different intervals at which each thyristor is conducting are shown in Table 1. The bridge output frequency is specified by the rate of sequencing these patterns. If we consider a Y-balanced load in $180^{\circ}$ conduction mode, there will be shift of $60^{\circ}$ between gating voltage. This will get us 3 phase balance voltage at output. The load could be star or delta connected. It must be taken care that any two switches of same leg eg. $Q_{3}$ and $\mathrm{Q}_{6}, \mathrm{Q}_{1}$ and $\mathrm{Q}_{4}$, or $\mathrm{Q}_{5}$ and $\mathrm{Q}_{2}$ should not be switched on at same time. This is to avoid short circuit across the input dc voltage supply. Similarly, two switches of same leg should not be switched off at same time as it will cause undefined ac output voltage and undefined state. If switches are turned off at same time, the output voltage will depend on polarity of line

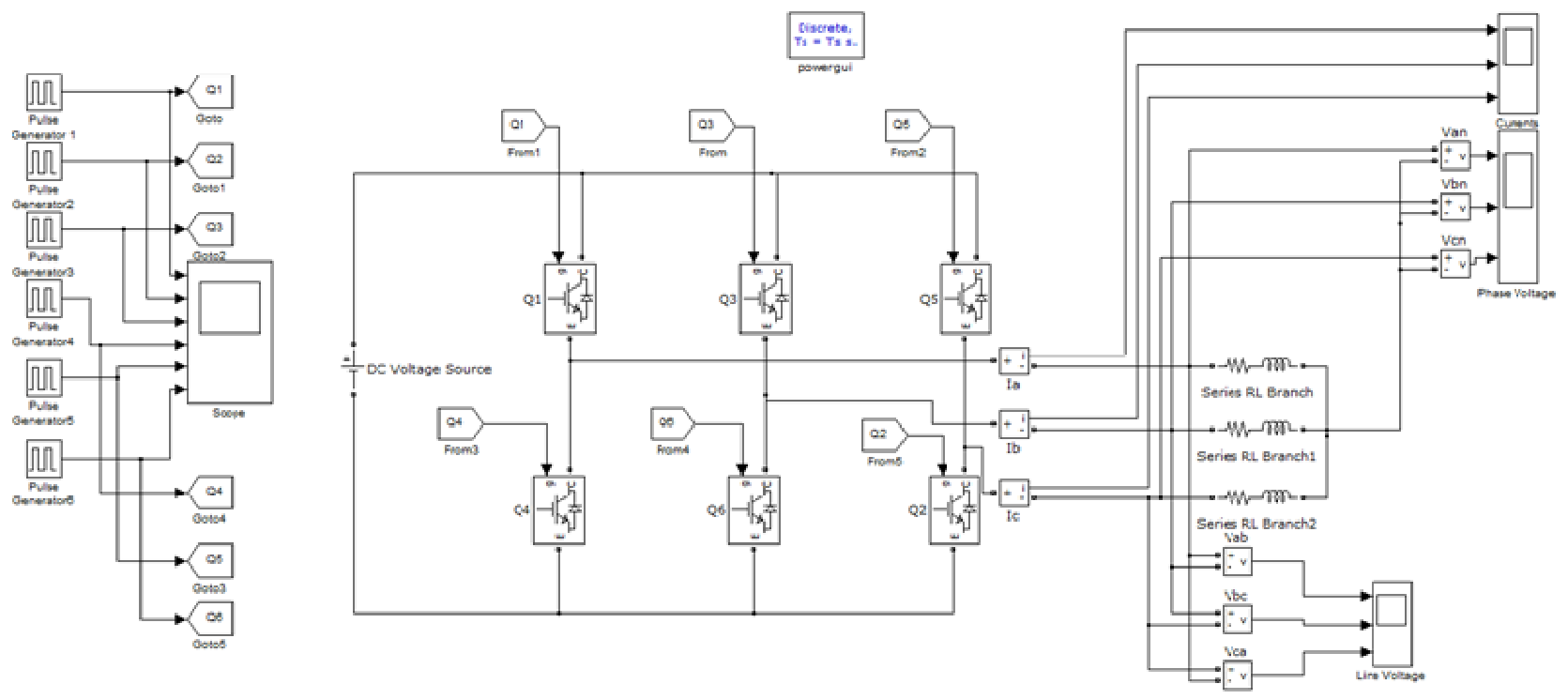

Figure 3 Simulink Model for three phase VSI 
In Mode 1 the switches $\mathrm{Q}_{5}, \mathrm{Q}_{6}$ and $\mathrm{Q}_{1}$ are turned on for the time interval $0^{0}<\mathrm{wt}<60^{\circ}$. As a result of this the terminals a and $c$ are connected to the positive terminal of input DC voltage and the terminal $b$ is connected to the negative terminal of the DC input. Thus the voltage across each branch is $\mathrm{Van}=\mathrm{Vcn}=\mathrm{Vdc} / 3$, $\mathrm{Vbn}=-2 \mathrm{Vdc} / 3$

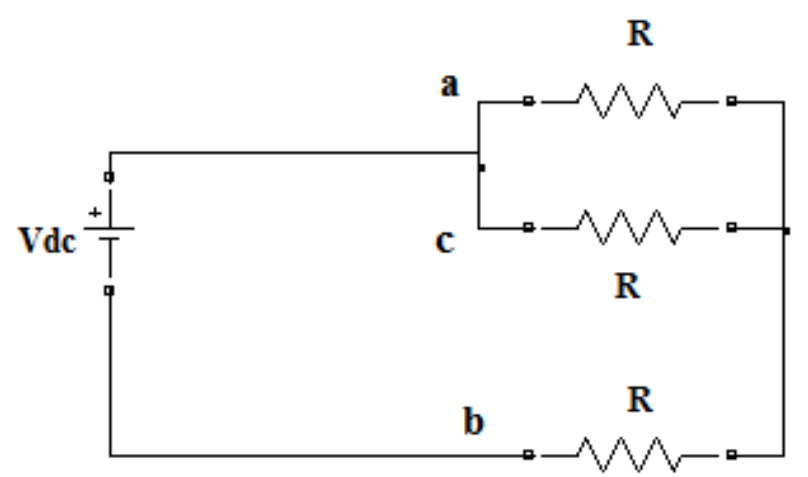

$0<\mathbf{w t}<60$

Figure 4 Mode 1 for 1800 VSI

Similarly, modes 2-6 are operated as per Table 1 below.

Table 1 Conduction Table for 1800 Three Phase VSI

\begin{tabular}{|l|l|l|}
\hline Mode & Duration (in degree) & Switches \\
\hline 1 & $0-60$ & S 5, S 6, S 1 \\
\hline 2 & $60-120$ & S 6, S 1, S 2 \\
\hline 3 & $120-180$ & S 1, S 2, S 3 \\
\hline 4 & $180-240$ & S 2, S 3, S 4 \\
\hline 5 & $240-300$ & S 3, S 4, S 5 \\
\hline 6 & $300-360$ & S 4, S 5, S 6 \\
\hline
\end{tabular}

Output phase voltage and line voltage for $180^{\circ}$ three phase VSI is shown in Table 2.

Few major drawbacks of $180^{\circ}$ conduction mode are:

- Magnitude of the $\mathrm{m}^{\text {th }}$ harmonic is $1 / \mathrm{m}$ times that of the fundamental.
- Two switches along the same leg (e.g. $\mathrm{Q}_{1}$ and $\mathrm{Q}_{4}$ ) may conduct simultaneously. If such condition happens, it will cause short circuit on the $\mathrm{dc}$ bus. This simultaneous conduction is result of absence of any time-delay between the on time of transistor $\mathrm{Q}_{4}$ and off-time of transistor $\mathrm{Q}_{1}$.

Table 2 Output Phase Voltage and Line Voltage for 1800 three phase VSI

\begin{tabular}{|c|c|c|c|c|c|c|}
\hline Mode & $\mathrm{V}$ an & $\mathrm{V}$ bn & $\mathrm{V} c \mathrm{cn}$ & $\mathrm{V} a b$ & $\mathrm{~V}$ bc & V ca \\
\hline 1 & $\mathrm{~V} \mathrm{~s} / 3$ & $-2 \mathrm{~V} \mathrm{~s} / 3$ & $\mathrm{~V} \mathrm{~s} / 3$ & $\mathrm{Vs}$ & $-V s$ & 0 \\
\hline 2 & $2 \mathrm{~V} \mathrm{~s} / 3$ & $-V \mathrm{~s} / 3$ & $-V \mathrm{~s} / 3$ & $\mathrm{~V} \mathrm{~s}$ & 0 & $-\mathrm{V} s$ \\
\hline 3 & $\mathrm{~V} \mathrm{~s} / 3$ & $\mathrm{~V} \mathrm{~s} / 3$ & $-2 \mathrm{~V} \mathrm{~s} / 3$ & 0 & $\mathrm{Vs}$ & $-\mathrm{V} s$ \\
\hline 4 & $-V \mathrm{~s} / 3$ & $2 \mathrm{~V} \mathrm{~s} / 3$ & $-V \mathrm{~s} / 3$ & $-V s$ & $\mathrm{Vs}$ & 0 \\
\hline 5 & $-2 \mathrm{~V} \mathrm{~s} / 3$ & $\mathrm{~V} \mathrm{~s} / 3$ & $\mathrm{~V} \mathrm{~s} / 3$ & $-V s$ & 0 & $\mathrm{~V} \mathrm{~s}$ \\
\hline 6 & $-V \mathrm{~s} / 3$ & $-V \mathrm{~s} / 3$ & $2 \mathrm{~V} \mathrm{~s} / 3$ & 0 & $-V s$ & V s \\
\hline
\end{tabular}

- Very poor quality of voltage/current is obtained especially in line-to-line voltage. Thus it requires big filters to be placed in between the converter and the motor. To overcome this, switching frequency may be increased, but it will further cause increase in switching losses.

\section{$2.2 \mathbf{1 2 0}^{0}$ Conduction Mode Three Phase VSI}

In $120^{\circ}$ conduction scheme each device conducts for $120^{\circ}$. At any instant of time, two switches will conduct simultaneously. At every $60^{\circ}$ interval any one switch will turn off and other will be turned on and start conducting [2]. But the advantage of this mode is that there is $60^{\circ}$ interval between turning on and off of switch in the same leg. This eliminates the possibility of short circuit. But as compared to $180^{\circ}$ conduction mode, in $120^{\circ}$ mode rms output value and switch utilization factor of switches is less. 
It is preferable for a star connected load because it provides a six step waveform across any phase. As each device conducts for $120^{\circ}$, only two devices are in conduction state at any instant. During the period $0^{0}$ to $60^{\circ}, \mathrm{Q} 1$ to Q6 are conducting. Load terminals $\mathrm{A}$ and $\mathrm{B}$ are connected to positive terminal and negative terminal of the source respectively. Load terminal $\mathrm{C}$ is in floating state.

Line Voltages:

$\mathrm{V} a b=\mathrm{V}$

$\mathrm{V} b \mathrm{c}=-\mathrm{V} / 2$

$\mathrm{V}$ ca $=-\mathrm{V} / 2$

In mode 1 the switches $\mathrm{Q}_{6}$ and $\mathrm{Q}_{1}$ are turned on for the time interval $0^{\circ}<w t<60^{\circ}$. As a result of this the terminals a is connected to the positive terminal of input DC voltage and the terminal $b$ is connected to the negative terminal of the DC input. Thus the voltage across each branch is $\mathrm{Van}=\mathrm{Vdc} / 2, \mathrm{Vbn}=-\mathrm{Vdc} / 2, \mathrm{Vcn}=0$

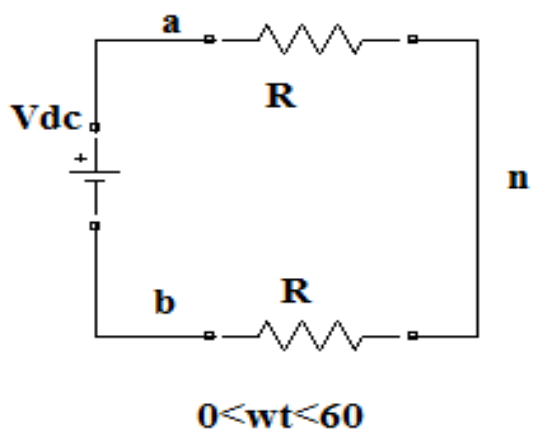

Figure 5 Mode 1 for 1200 VSI

Similarly modes 2-6 are operated according to Table 3. Output phase voltage and line voltage for $120^{\circ}$ three phase VSI is shown in Table 4

Advantages of $120^{\circ}$ three phase VSI are:

- Short circuit conduction of $180^{\circ}$ mode is overcome in $120^{\circ}$ mode inverter. In this inverter there is a $60^{\circ}$ interval between turning off of $S_{1}$ and turning $\mathrm{ON}$ of $\mathrm{S}_{4}$.During this $60^{\circ}$ interval, $\mathrm{S}_{1}$ can be commutated safely.

Table 3 Conduction Table for 1200 Three Phase VSI

\begin{tabular}{|l|l|l|}
\hline Mode & Duration (in degree) & Switches \\
\hline 1 & $0-60$ & S 6, S 1 \\
\hline 2 & $60-120$ & S 1, S 2 \\
\hline 3 & $120-180$ & S 2, S 3 \\
\hline 4 & $180-240$ & S 3, S 4 \\
\hline 5 & $240-300$ & S 4, S 5 \\
\hline 6 & $300-360$ & S 5, S 6 \\
\hline
\end{tabular}

Table 4 Output Phase Voltage and Line Voltage of 1200 three Phase VSI

\begin{tabular}{|l|l|l|l|l|l|l|}
\hline Mode & V an & V bn & V cn & V ab & V bc & V ca \\
\hline 1 & V s/2 & - V s/2 & 0 & V s & - V s/2 & - V s/2 \\
\hline 2 & V s/2 & 0 & $-\mathrm{V} \mathrm{s} / 2$ & $\mathrm{~V} \mathrm{~s} / 2$ & $\mathrm{~V} \mathrm{~s} / 2$ & $-\mathrm{V} \mathrm{s}$ \\
\hline 3 & 0 & $\mathrm{~V} \mathrm{~s} / 2$ & $-\mathrm{V} \mathrm{s} / 2$ & $-\mathrm{V} \mathrm{s} / 2$ & $\mathrm{~V} \mathrm{~s}$ & $-\mathrm{V} \mathrm{s} / 2$ \\
\hline 4 & $-\mathrm{V} \mathrm{s} / 2$ & $\mathrm{~V} \mathrm{~s} / 2$ & 0 & $-\mathrm{V} \mathrm{s}$ & $\mathrm{V} \mathrm{s} / 2$ & $\mathrm{~V} \mathrm{~s} / 2$ \\
\hline 5 & $-\mathrm{V} \mathrm{s} / 2$ & $0 \mathrm{~V} \mathrm{~s} / 2$ & $\mathrm{~V} \mathrm{~s} / 2$ & $-\mathrm{V} \mathrm{s} / 2$ & $-\mathrm{V} \mathrm{s} / 2$ & $\mathrm{~V} \mathrm{~s}$ \\
\hline 6 & 0 & $-\mathrm{V} \mathrm{s} / 2$ & $\mathrm{~V} \mathrm{~s} / 2$ & $\mathrm{~V} \mathrm{~s} / 2$ & $-\mathrm{V} \mathrm{s}$ & $\mathrm{V} \mathrm{s} / 2$ \\
\hline
\end{tabular}

In general this angular interval of $180^{\circ}$ exists between turning off of one device and turning on of the complementary device in the same leg. This $60^{\circ}$ period provide sufficient time for the outgoing switch to regain forward blocking capability.

- When compared to $180^{\circ}$ mode, switch utilization factor and rms output value are less in $120^{\circ}$ conduction mode.

\section{$2.3150^{\circ}$ Conduction Mode three phase VSI} In $150^{\circ}$ conduction mode of three phase VSI conduction period for each switch is $150^{0}$ [4-5]. The output phase voltage becomes 7 level, 12 step waveform, while $180^{\circ}$ and $120^{\circ}$ conduction modes have only 4 level and 3 levels 
respectively. The 12 switching patterns with $30^{\circ}$ duration are formed in this mode. 2 transistors conduct in one interval and 3 in next one and so on. The factors on which total harmonic distortion of the output voltage depends are conductive angle and power factor. Only conduction mode can be decided by designer, while power factor of load completely depends on load. So conduction mode must be selected such that output voltage must have high RMS value and low THD.

In mode 1 the switches Q1, Q2 and Q3 are turned on for the time interval $0^{0}<$ wt $<30^{\circ}$. Hence, terminal $\mathrm{c}$ is connected to the -ve terminal of the DC input while the terminals a and $b$ are connected to the +ve terminal of input DC voltage. Thus the voltage across each branch is

$\mathrm{Van}=\mathrm{Vbn}=\mathrm{Vdc} / 3, \mathrm{Vcn}=-2 \mathrm{Vdc} / 3$

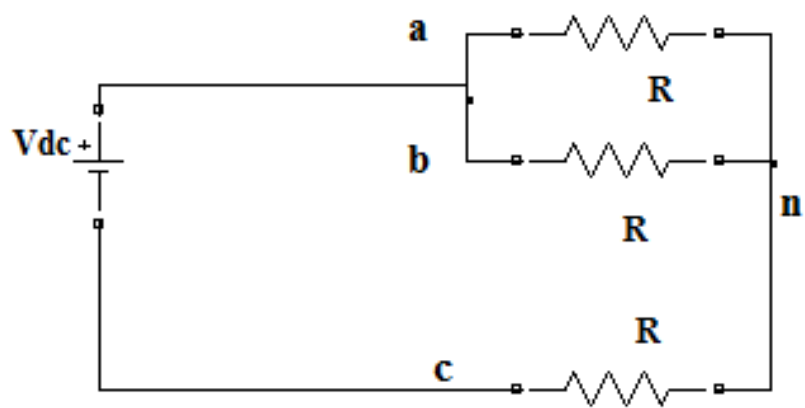

\section{$\mathbf{0}<\mathbf{w t}<\mathbf{3 0}$}

Figure 6 Mode 1 for 1500 VSI

Similarly mode 2-6 are operated according to conditions given in Table 5 and Output phase voltage and line voltage for $150^{\circ}$ three phase VSI is shown in Table 6

. The advantage of $150^{\circ}$ conduction mode three phases VSI are as follows:

- A $30^{\circ}$ gap time period is placed in between 2 series switches of same leg. It will be enough to avoid short circuit on input DC supply.
- It provides output phase voltage having 7 levels waveform, which is far much better as compared to only 3 and 4 levels in $120^{\circ}$ and $180^{\circ}$ modes respectively.

- This mode reduces the total harmonic distortion and distortion factor of output voltage wavefrms to much better extent.

- Lower Order Harmonics are eliminated to a greater extent in this mode.

Table 5 Conduction Table for 1500 Three Phase VSI

\begin{tabular}{|l|l|l|}
\hline Mode & Duration (in degree) & Switches \\
\hline 1 & $0-30$ & S 1, S 2, S 3 \\
\hline 2 & $30-60$ & S 2, S 3 \\
\hline 3 & $60-90$ & S 2, S 3, S 4 \\
\hline 4 & $90-120$ & S 3, S 4 \\
\hline 5 & $120-150$ & S 3, S 4, S 5 \\
\hline 6 & $150-180$ & S 4, S 5 \\
\hline 7 & $180-210$ & S 4, S 5, S 6 \\
\hline 8 & $210-240$ & S 5, S 6 \\
\hline 9 & $240-270$ & S 5, S 6, S 1 \\
\hline 10 & $270-300$ & S 6, S 1 \\
\hline 11 & $300-330$ & S 6, S 1, S 2 \\
\hline 12 & $330-360$ & S 1, S 2 \\
\hline
\end{tabular}

Table 6: Output Phase Voltage and Line Voltage for 1500 Three Phase VSI

\begin{tabular}{|l|l|l|l|l|l|l|}
\hline Mode & $\mathrm{V}$ an & $\mathrm{V}$ bn & $\mathrm{V} \mathrm{cn}$ & $\mathrm{V}$ ab & $\mathrm{V}$ bc & $\mathrm{V} \mathrm{ca}$ \\
\hline 1 & $\mathrm{Vs} / 3$ & $\mathrm{Vs} / 3$ & $-2 \mathrm{Vs} / 3$ & 0 & $\mathrm{Vs}$ & $-\mathrm{Vs}$ \\
\hline 2 & 0 & $\mathrm{Vs} / 2$ & $-\mathrm{Vs} / 2$ & $-\mathrm{Vs} / 2$ & $\mathrm{Vs}$ & $-\mathrm{Vs} / 2$ \\
\hline 3 & $-\mathrm{Vs} / 3$ & $2 \mathrm{Vs} / 3$ & $-\mathrm{Vs} / 3$ & $-\mathrm{Vs}$ & $\mathrm{Vs}$ & 0 \\
\hline 4 & $-\mathrm{Vs} / 2$ & $\mathrm{Vs} / 2$ & 0 & $-\mathrm{Vs}$ & $\mathrm{Vs} / 2$ & $\mathrm{Vs} / 2$ \\
\hline 5 & $-2 \mathrm{Vs} / 3$ & $\mathrm{Vs} / 3$ & $\mathrm{Vs} / 3$ & $-\mathrm{Vs}$ & 0 & $\mathrm{Vs}$ \\
\hline 6 & $-\mathrm{Vs} / 2$ & 0 & $\mathrm{Vs} / 2$ & $-\mathrm{Vs} / 2$ & $-\mathrm{Vs} / 2$ & $\mathrm{Vs}$ \\
\hline 7 & $-\mathrm{Vs} / 3$ & $-\mathrm{Vs} / 3$ & $2 \mathrm{Vs} / 3$ & 0 & $-\mathrm{Vs}$ & $\mathrm{Vs}$ \\
\hline 8 & 0 & $-\mathrm{Vs} / 2$ & $\mathrm{Vs} / 2$ & $\mathrm{Vs} / 2$ & $-\mathrm{Vs}$ & $\mathrm{Vs} / 2$ \\
\hline 9 & $\mathrm{Vs} / 3$ & $-2 \mathrm{Vs} / 3$ & $\mathrm{Vs} / 3$ & $\mathrm{Vs}$ & $-\mathrm{Vs}$ & 0 \\
\hline 10 & $\mathrm{Vs} / 2$ & $-\mathrm{Vs} / 2$ & 0 & $\mathrm{Vs}$ & $-\mathrm{Vs} / 2$ & $-\mathrm{Vs} / 2$ \\
\hline 11 & $2 \mathrm{Vs} / 3$ & $-\mathrm{Vs} / 3$ & $-\mathrm{Vs} / 3$ & $\mathrm{Vs}$ & 0 & $-\mathrm{Vs}$ \\
\hline 12 & $\mathrm{Vs} / 2$ & 0 & $-\mathrm{Vs} / 2$ & $\mathrm{Vs} / 2$ & $\mathrm{Vs} / 2$ & $-\mathrm{Vs}$ \\
\hline
\end{tabular}




\section{Simulation Results}

The stepped wave output voltage of an inverter when operated in various conducting modes consists of fundamental components and several harmonic components [6-7]. The purpose of analyzing the output of an inverter is to determine the harmonics in the output voltage waveform. Total Harmonic Distortion (THD) is the general harmonic index that is

$$
V_{a n 180}=\Sigma_{n=6 k \pm 1} \frac{2 V_{s}}{n \Pi} \sin n w t
$$

where, $\mathrm{k}=0,1,2, \ldots$

$$
\begin{gathered}
V_{a n 120}=\Sigma_{n=1,3,5, \ldots} \frac{2 V_{s}}{n \Pi} \cos \frac{n \Pi}{6} \sin n\left(w t+\frac{\Pi}{6}\right) \\
v_{a n_{-} 150^{\circ}}=\sum_{n=1,3,5, \cdots}^{\infty} \frac{V_{d}}{6 n \pi}\left[4+\cos \frac{n \pi}{6}+\cos \frac{n \pi}{3}-\cos \frac{2 n \pi}{3}-2 \cos \frac{5 n \pi}{6}\right. \\
\left.-\cos \frac{7 n \pi}{6}-\cos \frac{4 n \pi}{3}+\cos \frac{5 n \pi}{3}+2 \cos \frac{11 n \pi}{6}\right] \cdot \sin n\left(\omega t+\frac{\pi}{6}\right)
\end{gathered}
$$

FFT analysis of line current with wave forms are shown below:
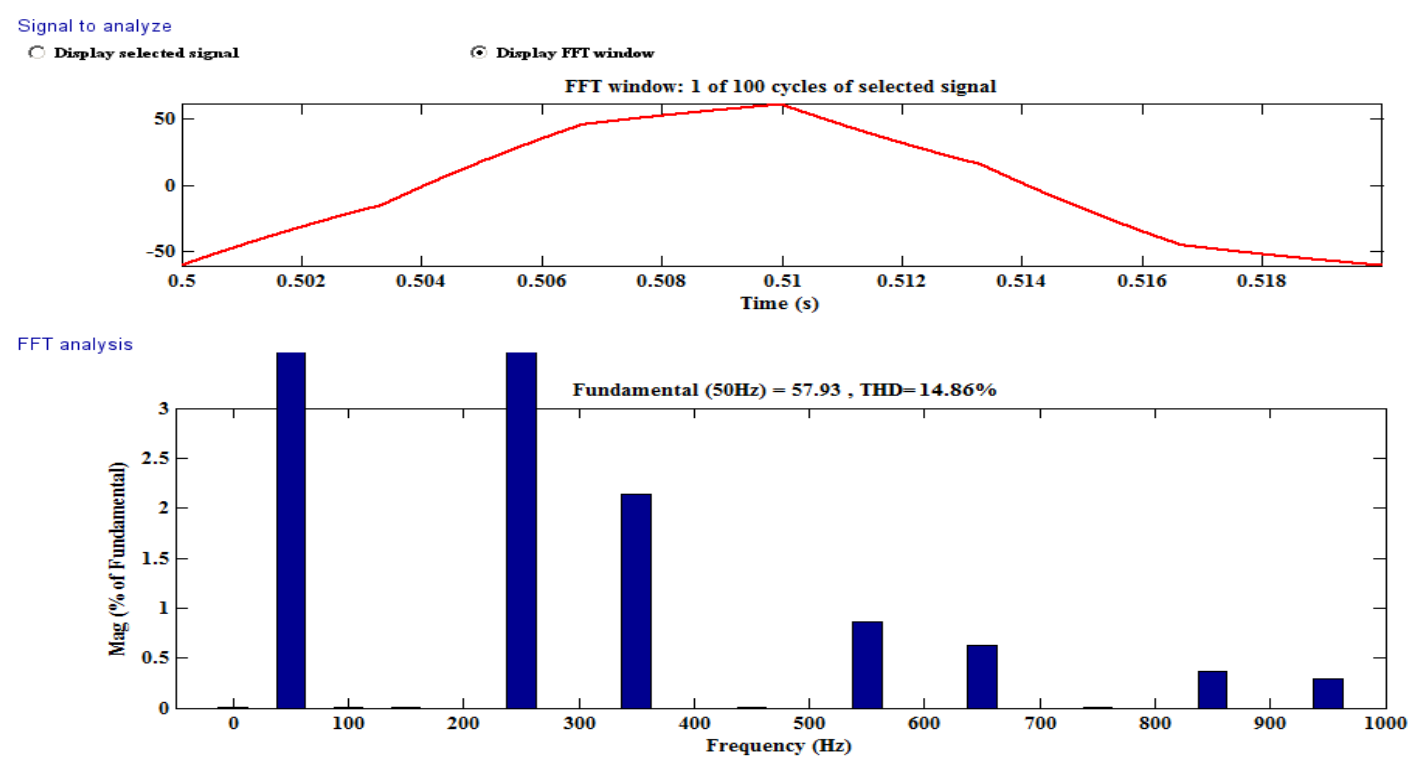

Figure 7 (a) FFT analysis of 1800 three phase VSI 
Chandrakar, 2019. Comparison and analysis of different conduction modes of three phase voltage source inverter
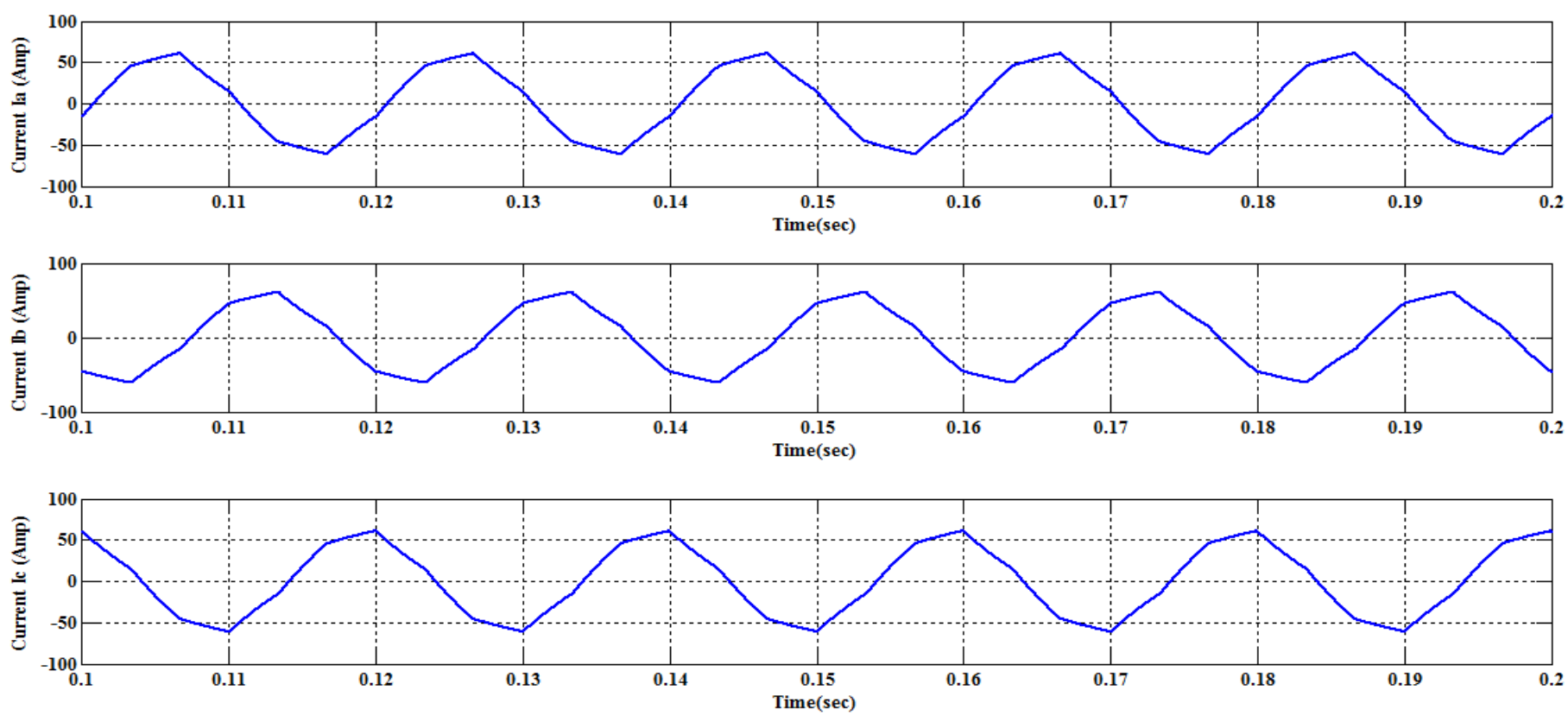

Figure 7 (b) Output Line Current of 1800 Three Phase VSI
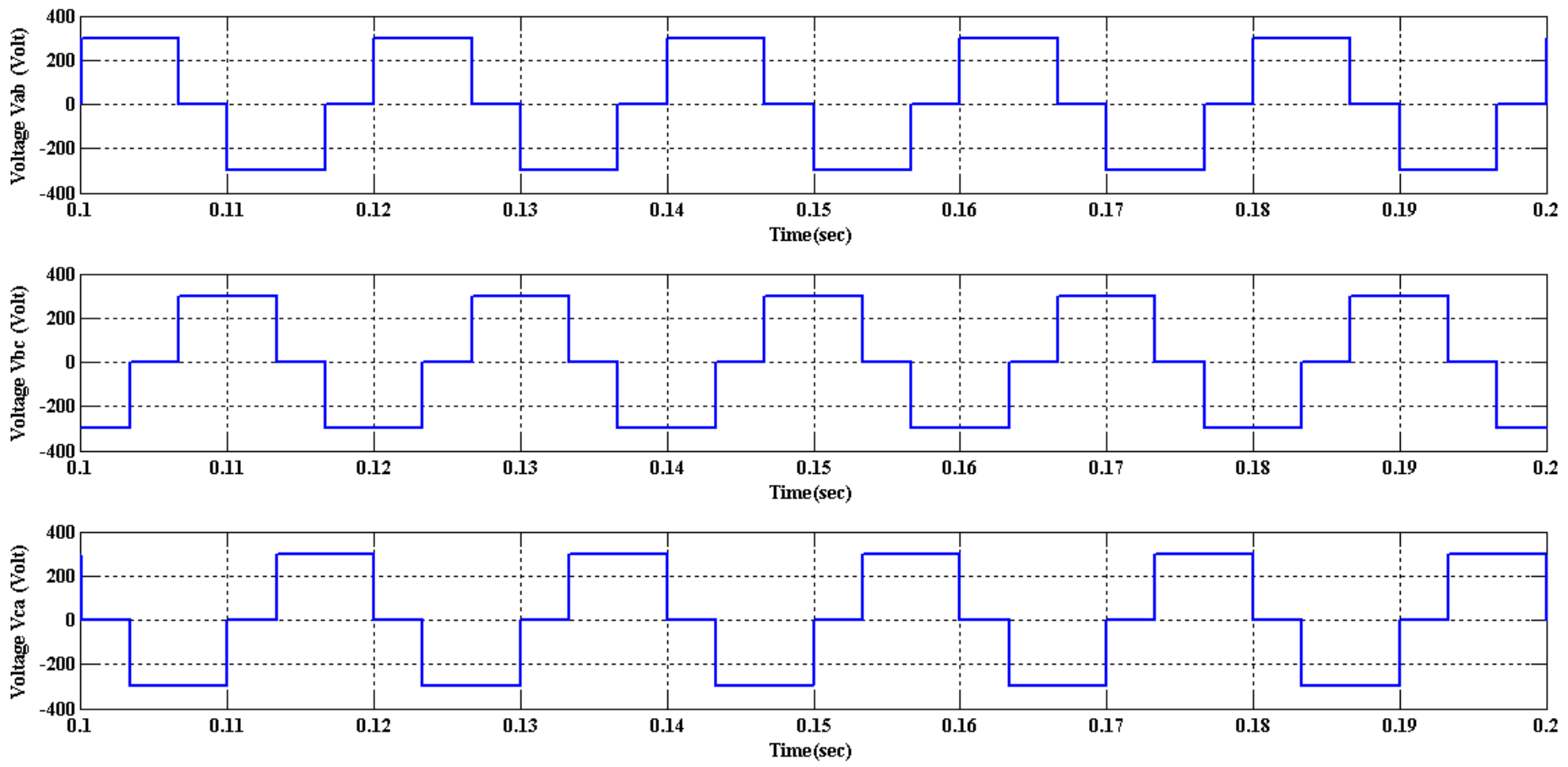

Figure 7 (c) Output Line Voltage of 1800 Three Phase VSI 


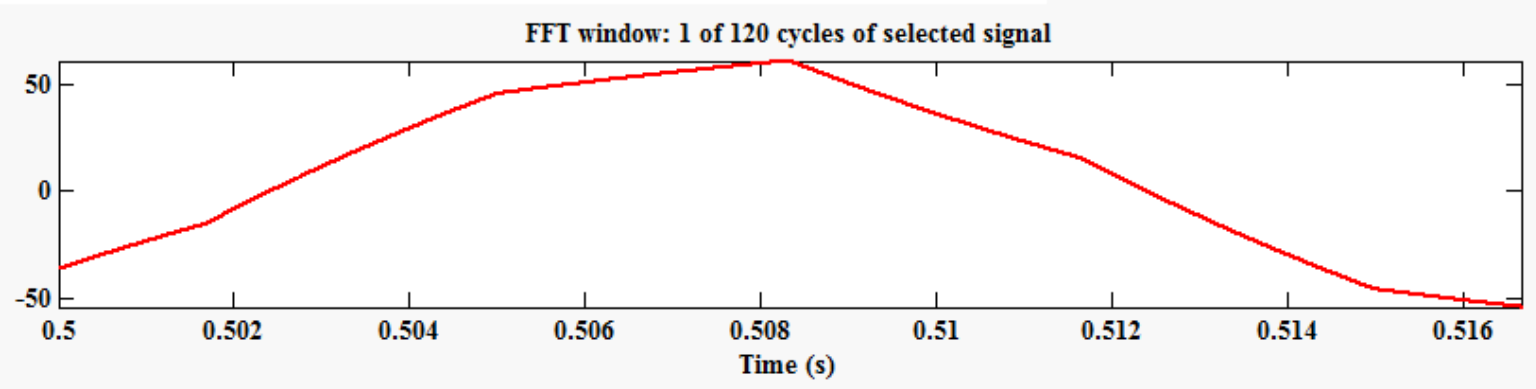

FFT analysis

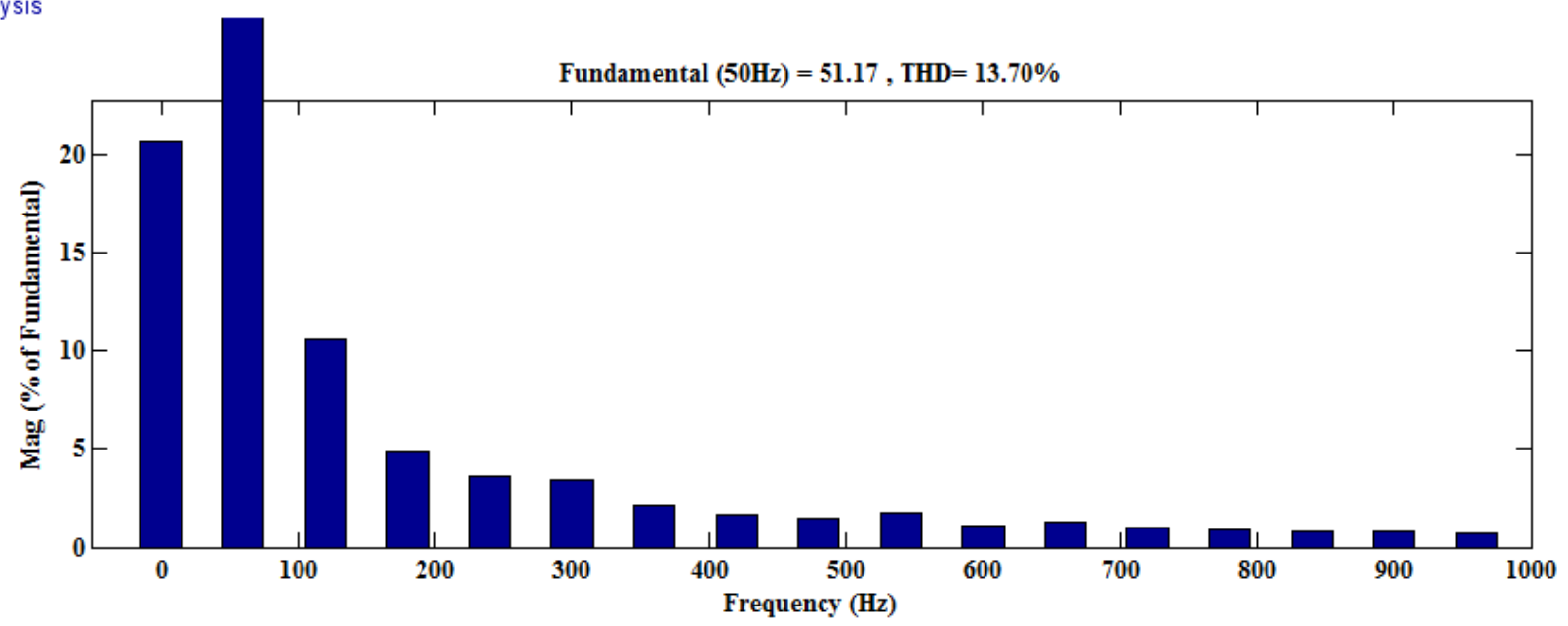

Figure 8 (a) FFT analysis of 1500 three phase VSI
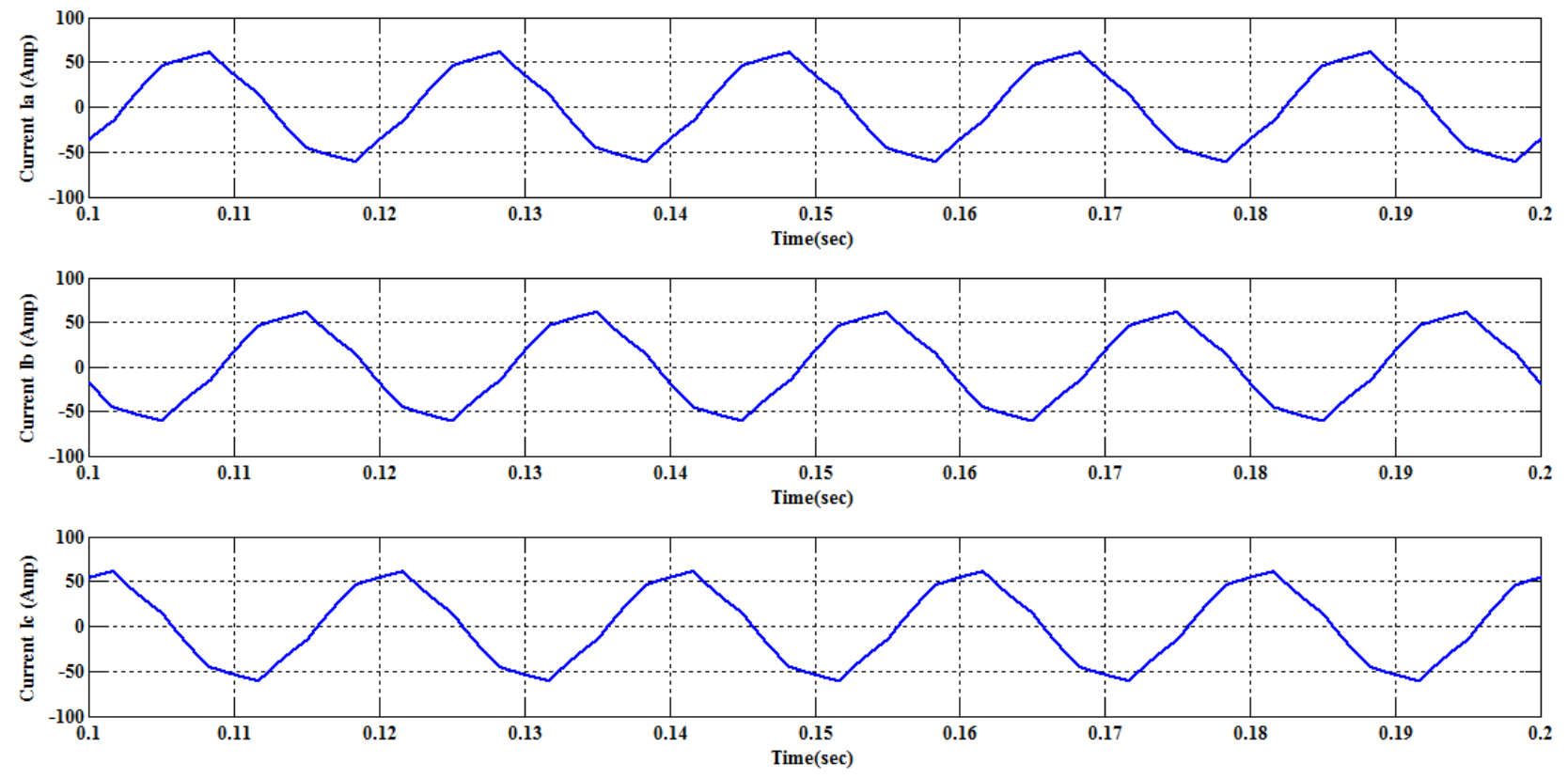

Figure 8 (b) Output Line Current of 1500 Three Phase VSI 

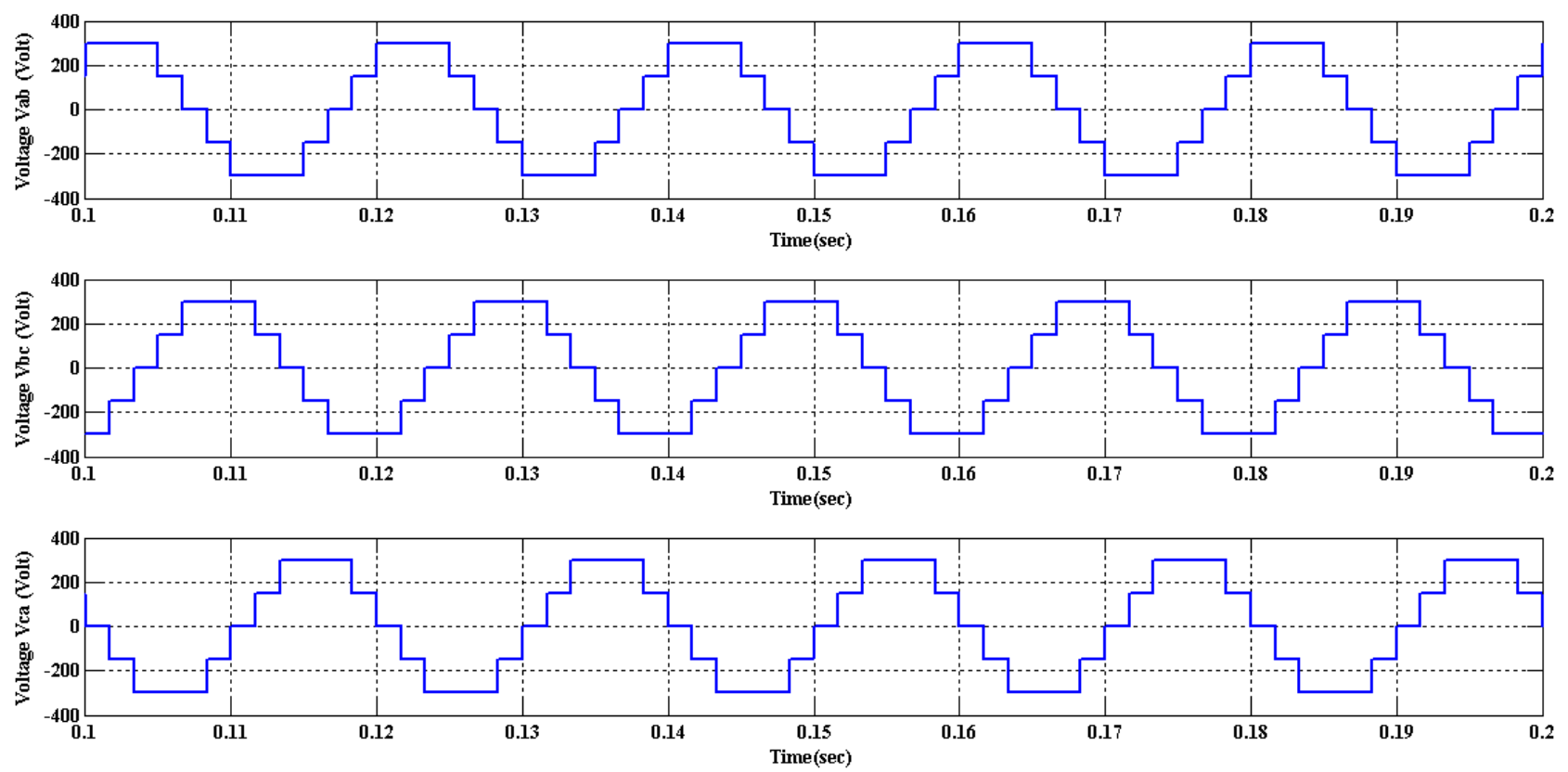

Figure 8 (c) Output Line Voltage of 1500 Three Phase VSI

Signal to analyze

$\odot$ Display selected signal $\odot$ Display FFT window

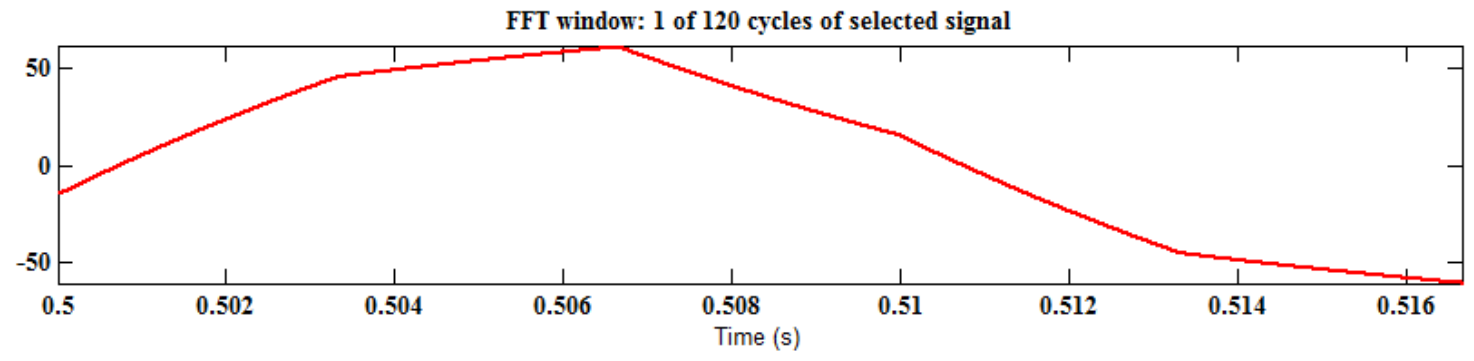

-FFT analysis

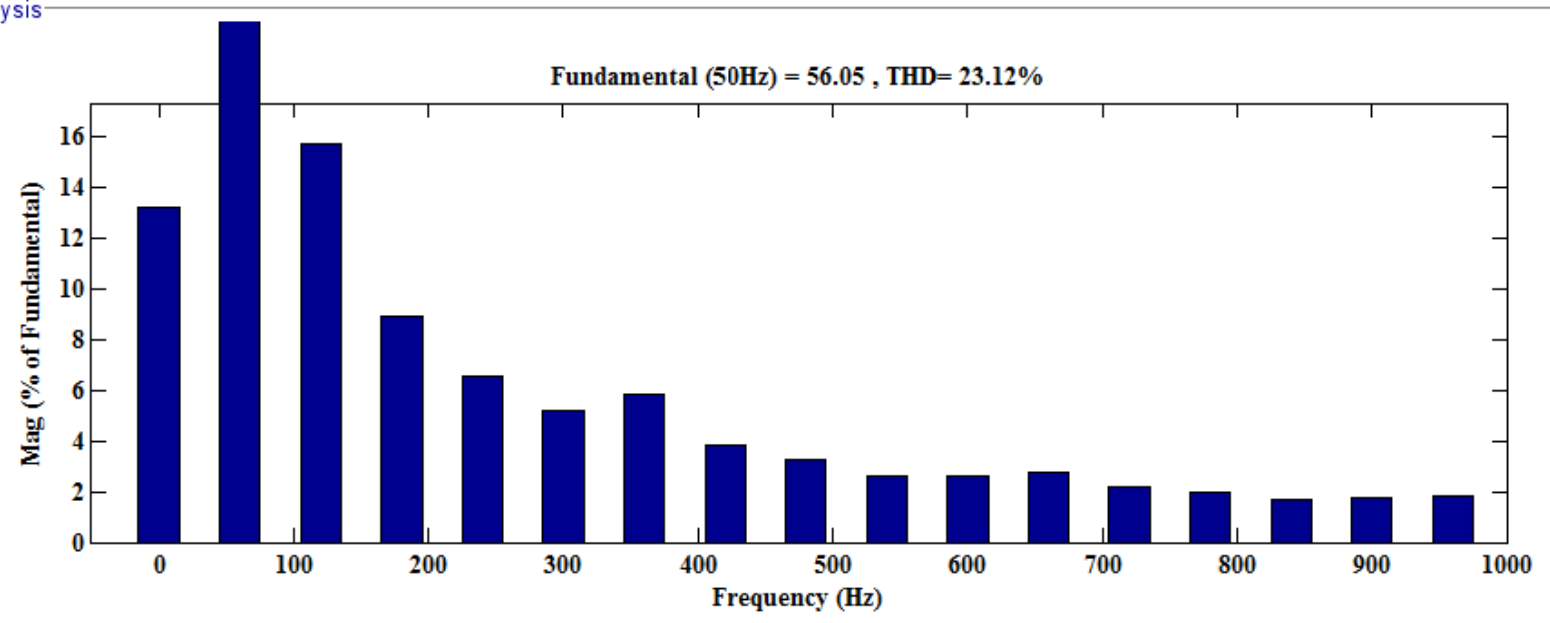

Figure 9 (a) FFT analysis of 1200 three phase VSI 

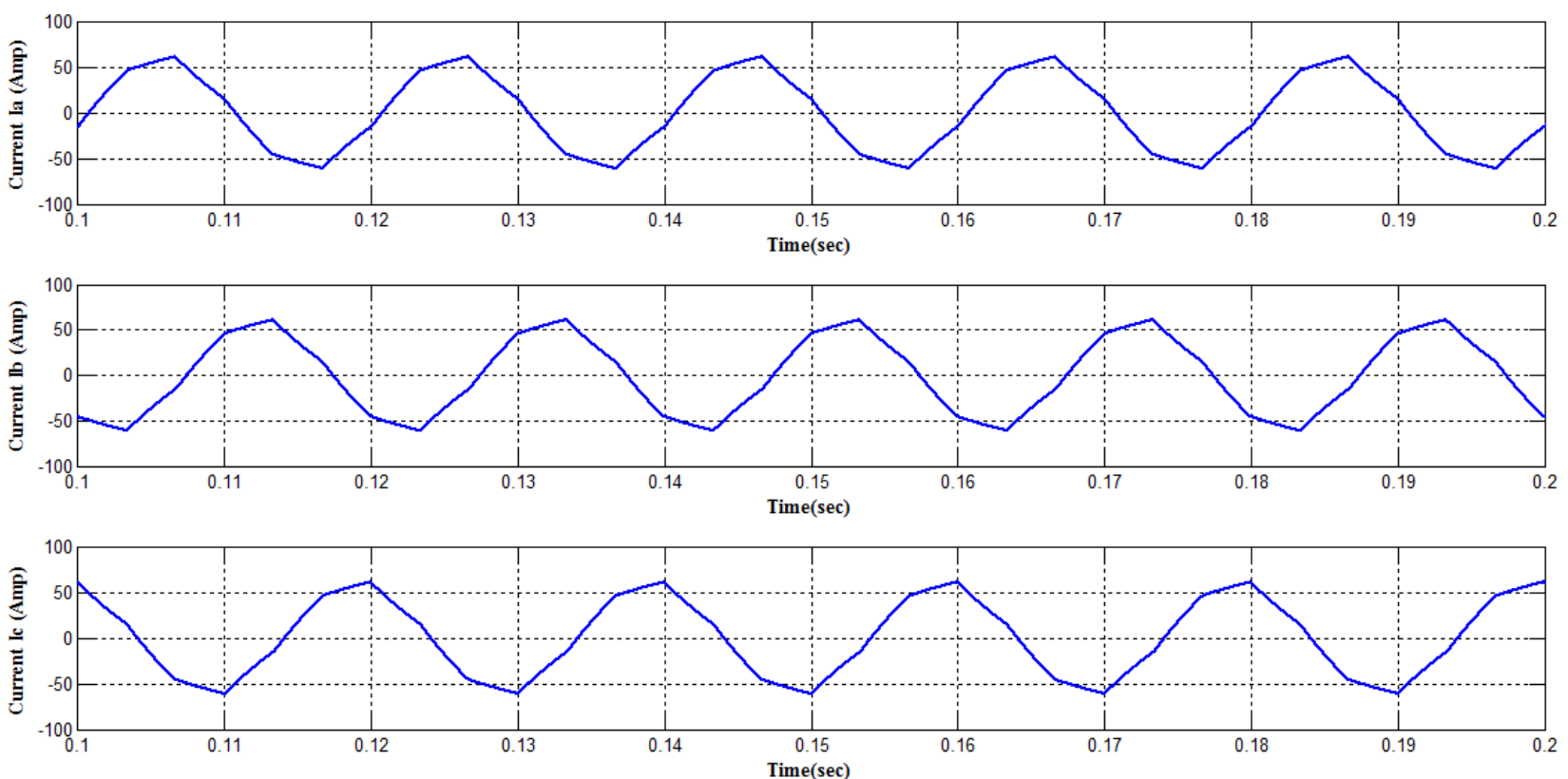

Figure 9 (b) Output Line Current of 1200 Three Phase VSI

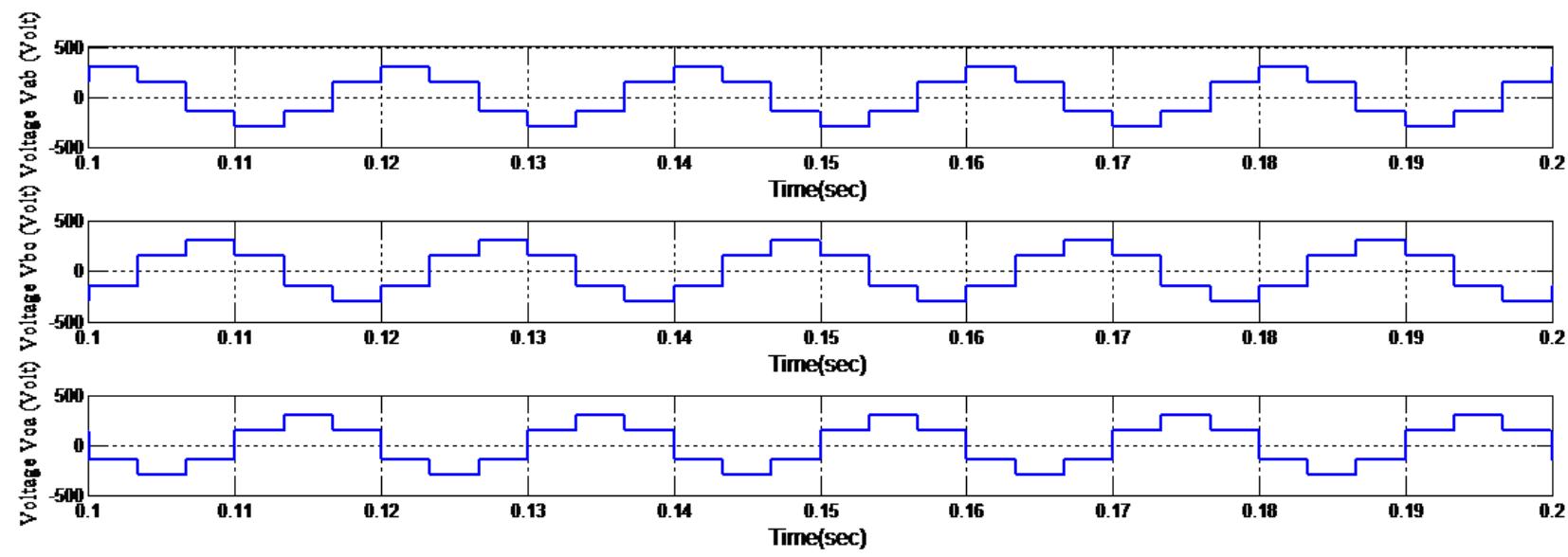

Figure 9 (c) Output Line Voltage of 1200 Three Phase VSI

On the basis of FFT analysis following observation is obtained:

Table 7 Comparison of THD in different modes

\begin{tabular}{|l|l|l|}
\hline Mode & $\begin{array}{l}\text { Magnitude } \\
\text { fundamental (\%) }\end{array}$ & $\begin{array}{l}\text { THD } \\
(\%)\end{array}$ \\
\hline $180^{0}$ & 57.93 & 14.86 \\
\hline $120^{\circ}$ & 56.05 & 14.12 \\
\hline $150^{\circ}$ & 51.17 & 13.70 \\
\hline
\end{tabular}

\section{Conclusion}

In this article, simulink model for 3 phase Volatage Source Inverter (VSI) has been developed and tested in MATLAB/SIMULINK environment for different conduction modes. The method used to analyse the harmonic spectra of different output current is by comparing and plotting simulation results. THD (Total Harmonic Distortion) are also compared 
to get a clear result. It is known that output with minimum THD will have minimum losses hence more efficient. The input is DC voltage source and output are 3 phase sinusoidal voltage in dc-to-ac inverter which are analysed in this paper. The frequency of output is lower than the switching frequency. Calculation of performance parameters i.e., THD for output voltages and THD for output current has been done using M-file coding. Using MATLAB

\section{References}

1. Bhimbra, P.S. (2012). Power Electronics. Delhi: Khanna publication.

2. Rashid, M. H. (2001). Power Electronics handbook: Circuits, Devices \&applications. NJ: Pearson publication.

3. Oguchi, K., Hama, H., \& Kubota, T. (1997, October). Multilevel current-source and voltage-source converter systems coupled with harmonic canceling reactors. In IAS'97. Conference Record of the 1997 IEEE Industry Applications Conference Thirty-Second IAS Annual Meeting (Vol. 2, pp. 1300-1308). IEEE. 4. Helal, A. A., \& Saied, M. H. (2008, October). Dynamic voltage restorer adopting $150^{\circ}$ conduction angle VSI. In 2008 IEEE Canada Electric Power Conference (pp. 1-6). IEEE.

5. Iqbal, A., \& Moinuddin, S. (2007, December). Assessment of torque pulsation in inverterd fed three-phase induction motor drive for $180^{\circ}$ and $150^{\circ}$ conduction modes. In 2007 IET-UK International Conference on Information and Communication Technology in Electrical Sciences (ICTES 2007) (pp. 323328). IET.

6. Grotzbach, M., \& Redmann, R. (2000). Line current harmonics of VSI-fed adjustable-speed
Simulation models, it was found that for RL of resistance equals to $1 \Omega$ and inductance equals to $5 \mathrm{mH}$, THD is maximum in 1800 conduction mode and minimum in 1500 conduction mode.

\section{Conflict of interest}

The authors declare no conflict of interest.

drives. IEEE Transactions on Industry Applications, 36(2), 683-690.

7. Chang, G. W., \& Chen, S. K. (2005). An analytical approach for characterizing harmonic and interharmonic currents generated by VSIfed adjustable speed drives. IEEE Transactions on Power Delivery, 20(4), 2585-2593.

8. Saied, M. H., Mostafa, M. Z., AbdelMoneim, T. M., \& Yousef, H. A. (2006, July). On three-phase six-switches voltage source inverter: A $150^{\circ}$ conduction mode. In 2006 IEEE International Symposium on Industrial Electronics (Vol. 2, pp. 1504-1509). IEEE. 